\title{
REVIEW
}

\section{Safety Review: Dose Optimization of Somatostatin Analogs in Patients with Acromegaly and Neuroendocrine Tumors}

William H. Ludlam · Lowell Anthony

Received: July 22, 2011 / Published online: September 28, 2011

(c) The Author(s) 2011. This article is published with open access at Springerlink.com

\section{ABSTRACT}

Introduction: Patients with either acromegaly or neuroendocrine tumors (NET) can be treated with somatostatin analogs to relieve symptoms and improve disease control. However, there is an absence of large clinical trials specifically designed to document the safety when increases in somatostatin analog dosing are needed in patients who do not achieve their treatment goals. To fully explore and communicate any potential risks, we conducted a literature review and present a summary of the studies documenting the safety and tolerability of dose optimization with somatostatin analogs in patients with acromegaly and NET. Methods: A literature search was undertaken to find clinical studies specifically reporting the effects of dose titration using the depot formulations of the somatostatin analogs,

William H. Ludlam

Seattle Pituitary Center, Swedish Neuroscience Institute, Seattle, WA, USA

Lowell Anthony ( $₫)$

Markey Cancer Center, University of Kentucky,

Lexington, KY, USA. Email: lowell.anthony@uky.edu octreotide long-acting repeatable (LAR) or lanreotide, in patients with acromegaly and NET. Results: Publications that described the treatment and management of patients with acromegaly and NET were reviewed. The rationale for dose optimization, including high-dose treatment in patients who are inadequately controlled on conventional doses and the safety and tolerability of somatostatin analogs, is discussed. Conclusion: A review of published clinical studies demonstrates that dose optimization provides additional biochemical control in patients with acromegaly and NET who are inadequately controlled with conventional starting doses of octreotide LAR and lanreotide ATG. The benefits of dose optimization include improved efficacy without a significant change in the recorded adverse events and the tolerability of the treatment. Therefore, patient response to treatment should be routinely monitored and their somatostatin analog dose increased or decreased thereafter according to their individual response.

Keywords: acromegaly; dose optimization; lanreotide; neuroendocrine tumors; octreotide; safety; somatostatin analogs 


\section{INTRODUCTION}

Until the development of the first somatostatin analog nearly three decades ago, patients who were diagnosed with acromegaly, a rare hormonal disorder caused by a pituitary adenoma, or neuroendocrine tumors (NET), malignant solid tumors that arise from neuroendocrine cells throughout the body, were limited in treatment to surgery or radiotherapy. Despite these treatment options, the negative impact on the patient's quality of life from either disease remains considerable. ${ }^{1,2}$ If the progression of these diseases is recognized early and/or the patient is determined to be a suitable candidate, surgical resection of the tumor is the first-line, and most effective, treatment for either condition. However, it is common for both acromegaly and NET to remain undiagnosed until late in the progression of the disease when the suitability of the patient and the effectiveness of surgery may be reduced. Determining the method of treatment for acromegaly and NET is dependent on many variables. Although surgery is considered the first-line treatment, major progress in the management of both diseases has been made through the development and clinical use of highly specific and selective pharmacological agents. Currently, the options for the medical treatment of acromegaly include the use of dopamine agonists, somatostatin analogs, and growth hormone (GH) receptor antagonists. ${ }^{3}$ The medical treatment options for patients with NET include cytotoxic therapies with chemotherapy agents, inhibitors of cellular signaling pathways (tyrosine kinase, angiogenesis, or mammalian target of rapamycin [mTOR] inhibitors), or the use of somatostatin analogs to treat the symptoms associated with peptide-secreting NET. ${ }^{4}$ Although the choice of treatment may depend on the degree of differentiation and progression of the disease, the use of somatostatin analogs as a medical therapy to treat acromegaly and NET has become an important approach for controlling disease progression and the mainstay for the medical treatment of these diseases.

Outside of the US, the somatostatin analogs octreotide and lanreotide are indicated for the treatment of both acromegaly and the severe diarrhea/flushing episodes associated with metastatic carcinoid tumors. In the US, lanreotide is indicated only for the treatment of acromegaly. Both somatostatin analogs have been shown to reduce the symptoms and delay progression of these diseases. ${ }^{5-7}$ The therapeutic effect of somatostatin analogs occurs via the inhibition of a large number of endocrine secretory processes that are coupled to the binding/ activation of the G-protein coupled somatostatin receptors (sst) present on the surface of a variety of cell types. There are five sst isoforms $\left(\mathrm{sst}_{1-5}\right)$ and, although the most prevalent sst found on the cell surface of pituitary adenomas and NET are sst $_{2}$ and sst $_{5}$, variable receptor expression may be a reason some patients do not respond fully to initial therapy (20 mg/28 days for octreotide long-acting repeatable [LAR] and $90 \mathrm{mg} / 28$ days for lanreotide depot) and experience residual or breakthrough symptoms. ${ }^{8}$ In light of this need for additional therapy, recent consensus treatment guidelines for patients with acromegaly ${ }^{3,9}$ and $\mathrm{NET}^{10,11}$ have been updated to include titration of the somatostatin analog dose (ie, dose optimization). These guidelines recommend increasing the somatostatin analog dose in response to the patient's need for additional symptom control or decreasing the dose if the patient has shown signs of improvement. In some patients, standard dosing is not sufficient to achieve symptom control and high-dose somatostatin analog therapy may 
be considered in an effort to control the disease. Due to the rarity of these diseases, large clinical studies documenting the efficacy and safety of somatostatin analog therapy in hundreds of patients with acromegaly or NET do not exist. Consequently, numerous small studies are available for review; however, these studies were designed to demonstrate the efficacy of somatostatin analog treatment and only briefly report the general safety issues associated with dose optimization. To determine whether there is any additional safety risk associated with increasing the somatostatin analog dose, the results from these clinical studies were reviewed and any changes in adverse events following dose optimization were documented. The results of this review demonstrate that the practice of dose optimization, already known to improve the efficacy of somatostatin analog therapy, does not lead to a significant increase in adverse events. The presentation of these studies together will give clinicians the opportunity to review the clinical results from numerous patients, and may expand their understanding regarding the treatment of these diseases.

\section{MATERIALS AND METHODS}

A literature search of PubMed from January 1965 to September 2010 was performed using the search terms "acromegaly" or "neuroendocrine tumor" and "dose optimization" or "dose titration." Studies designed to evaluate the patient response to somatostatin analog therapy (octreotide LAR or lanreotide depot), including treatment at an increased dose or an increased frequency, were selected. Additionally, studies where dose optimization was undertaken, but was not the objective of the study, were included in the review. Related articles in non-peerreviewed journals and in languages other than English were excluded.

\section{RESULTS}

\section{Acromegaly}

The yearly incidence of acromegaly is roughly three new cases per million and the prevalence of acromegaly worldwide is estimated to be around $40-70$ cases per million. ${ }^{12,13}$ However, the increasing number of patients being diagnosed with elevated insulin-like growth factor-1 (IGF-1) levels may indicate that acromegaly is underrecognized clinically and could in fact be more common. ${ }^{14}$ Acromegaly is primarily caused by a GH-secreting pituitary adenoma that results in the hepatic over-production of IGF-1. ${ }^{15}$ Patients with untreated acromegaly experience a two- to threefold increase in mortality ${ }^{16,17}$ and a decrease in quality of life compared to healthy controls. ${ }^{18}$ Controlling GH and IGF-1 hypersecretion is the primary goal of treatment as reducing GH and IGF-1 levels in circulation has been shown to lower mortality rates to levels similar to that of the normal population. ${ }^{17,19}$ The characteristic signs and symptoms in patients with acromegaly (Figure 1) can range from physical signs of acral and musculoskeletal overgrowth to major systemic complications such as diabetes or impaired glucose tolerance, cardiovascular disease, or respiratory diseases that may ultimately contribute to the increase in mortality. ${ }^{15,20}$

\section{Treatment Options for Patients with Acromegaly}

The diagnosis and treatment of patients with acromegaly begins with biochemical confirmation of increased GH and IGF-1 levels followed by surgical or medical treatment (Figure 2). Complete biochemical control is defined as serum $\mathrm{GH}<1 \mu \mathrm{g} / \mathrm{L}$ without oral glucose load and normalization of serum IGF-1 levels compared to age- and sex-matched controls. ${ }^{3,21}$ The goals 
Figure 1. Signs and symptoms of acromegaly.

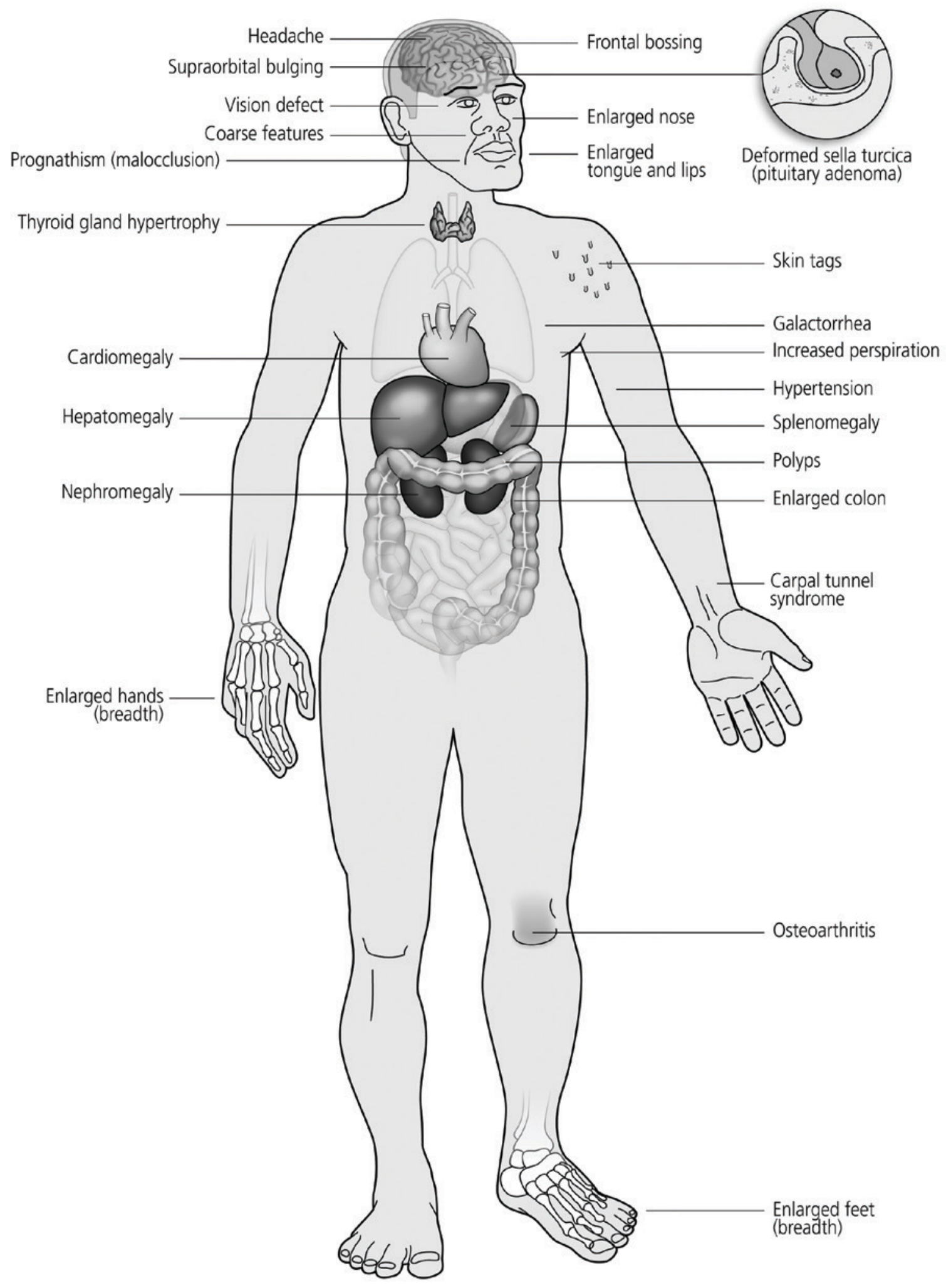


of treatment are to attain biochemical control, control tumor growth, and prevent recurrence. ${ }^{15,22}$ For most patients, transsphenoidal adenomectomy (TSA) by a dedicated and experienced pituitary neurosurgeon is the first-line treatment option. ${ }^{23-26}$ In addition to surgical treatment, the American Association of Clinical Endocrinologists (AACE) reviews the pharmacological options for the treatment of acromegaly and recommends medical therapy for the treatment of persistent acromegaly and for treatment of patients who are not candidates for surgery. ${ }^{3,21}$ The options for medical therapy include: somatostatin analogs, dopaminereceptor agonists, and GH-receptor analogs. Somatostatin analogs are the first choice ${ }^{21}$ and should be considered before undergoing surgery to improve severe co-morbidities that prevent or could complicate immediate surgery, ${ }^{27}$ as a first-line therapy when there is a low probability of surgical cure, ${ }^{28,29}$ after surgery has failed to achieve biochemical control, or in combination with radiation therapy. ${ }^{3} \mathrm{GH}-$-receptor analogs (ie, pegvisomant) are only effective in lowering IGF-1 levels and are typically used when other treatments have proven to be ineffective. The limited clinical data report that dopamine receptor agonists (ie, cabergoline and bromocriptine) are far less effective than either somatostatin analogs or GH-receptor blockers and are typically used in combination with somatostatin analog therapy.

\section{Somatostatin Analog Therapy in Patients with Acromegaly}

Somatostatin analogs have a well-established efficacy profile and patients do not typically discontinue treatment due to adverse events. A recent meta-analysis reviewed the efficacy results of more than 600 patients (regardless of somatostatin analog responsiveness). ${ }^{30}$ The analysis determined that treatment with long-acting somatostatin analogs as secondary therapy improved biochemical control. Specifically, the reported proportion of patients in whom there was a reduction in GH level $(<2.5 \mu \mathrm{g} / \mathrm{L})$ and normalization of IGF-1 was $57 \%$ and $67 \%$, respectively, following octreotide LAR therapy, and $48 \%$ and $47 \%$, respectively, following therapy with lanreotide depot. ${ }^{30}$ However, efficacy results vary greatly among studies and are dependent on the patient population, the definition of response, and the outcome of previous treatments. The safety of octreotide LAR in the treatment of acromegaly was initially evaluated in three phase 3 studies in 261 patients, including 209 exposed for 48 weeks and 96 exposed for greater than 108 weeks. Most patients received a starting dose of 20 mg every 4 weeks intramuscularly. The dose was titrated based on efficacy and tolerability to a final dose of 10-60 mg every 4 weeks. Adverse events occurring in $>10 \%$ of patients were mostly gastrointestinal (diarrhea, abdominal pain, and flatulence) and a few patients discontinued therapy because of these symptoms. Other adverse events included gall-bladder abnormalities (gallstones, sludge without stones, and biliary duct dilation), headache/nausea, alopecia, injection-site pain, hypertension, and fatigue. Similarly, the safety of lanreotide depot was evaluated in seven studies that included a total of 416 patients. The most commonly reported adverse reactions reported by $>5 \%$ of patients were gastrointestinal disorders (diarrhea, abdominal pain, nausea, constipation, flatulence, vomiting, and loose stools), cholelithiasis and gall-bladder sludge, and injection-site reactions. ${ }^{31}$ Both somatostatin and somatostatin analogs inhibit the secretion of insulin and glucagon. Therefore, patients may experience hypoglycemia or hyperglycemia and blood glucose levels should be monitored in patients with co-morbid conditions, such as diabetes mellitus, when treatment is initiated 
Figure 2. The diagnosis and treatment of acromegaly. CT=computed tomography; GH=growth hormone; GHRH=growth hormone-releasing hormone; IGF-1=insulin-like growth factor 1; MRI=magnetic resonance imaging; SRL=somatostatin receptor ligand. (C) 2006, The New England Journal of Medicine, reproduced with permission. Melmed Set al. (2006). N EnglJ Med. 355:2558-2573. ${ }^{15}$

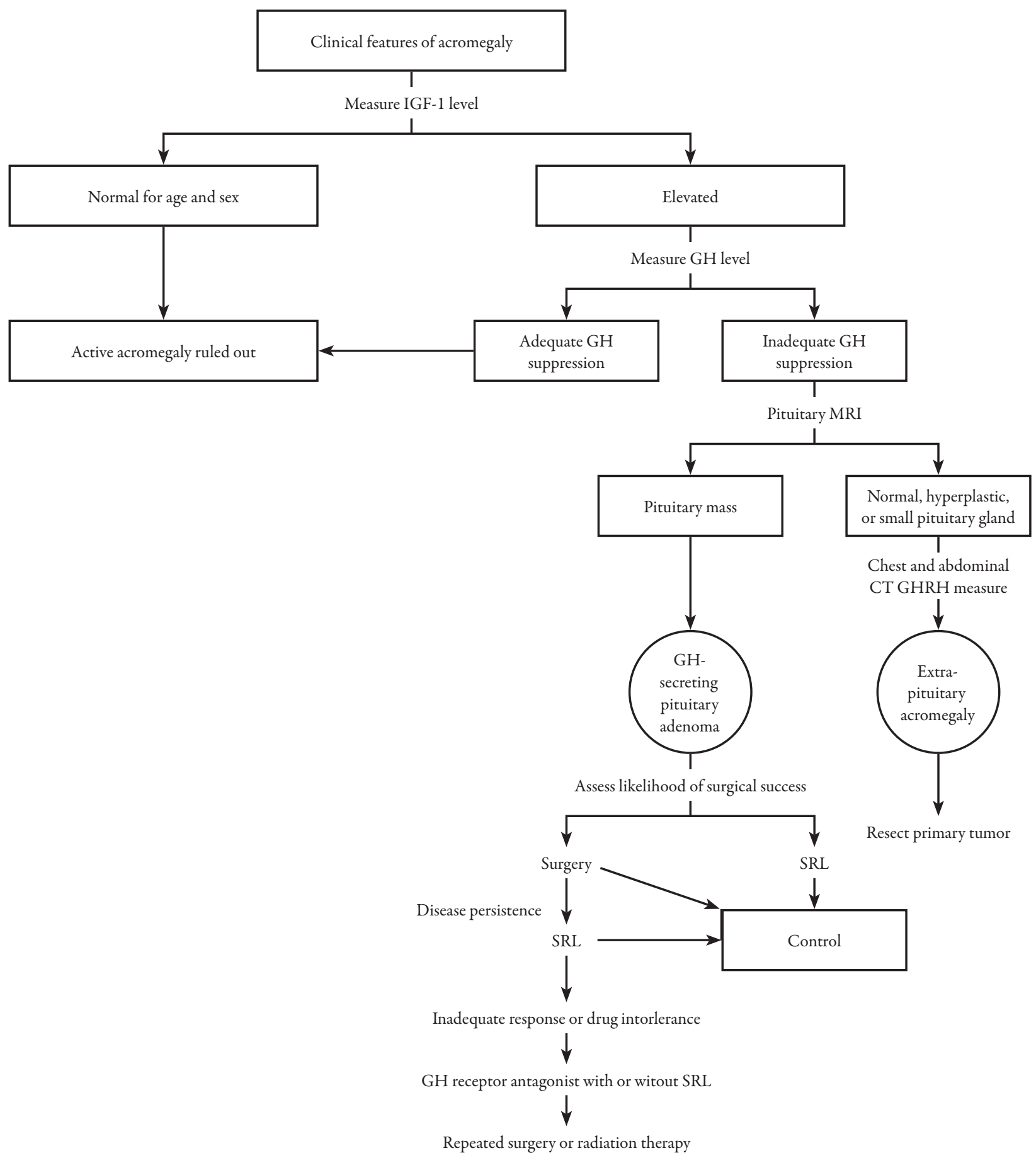


or when the dose is altered. ${ }^{20}$ Additionally, complications from somatostatin analog therapy include hypothyroidism due to the suppression of thyroid-stimulating hormone secretion and cardiac function abnormalities, such as bradycardia, arrhythmias, and conduction abnormalities.

\section{Rationale for Dose Optimization in Patients with Acromegaly}

Control of both GH and IGF-1 can lead to both a reversal of co-morbidities and a reduction in the risk of premature mortality. ${ }^{16,17,32}$ In patients with acromegaly, the approved starting dose for somatostatin analog therapy was determined in pharmacokinetic and pharmacodynamic studies. ${ }^{31,33}$ Subsequent studies have shown that not all patients at the starting dose report a complete normalization of GH and IGF-1 and symptom control may vary greatly from one patient to another. ${ }^{34-36}$ Consensus guidelines recognized this and reacted by updating the treatment guidelines to recommend adjusting the somatostatin analog dose in patients who do not respond to initial treatment up to the highest approved dose and, in some cases, to a maximum of $60 \mathrm{mg} / \mathrm{month}$ for octreotide LAR and $120 \mathrm{mg} / \mathrm{month}$ for lanreotide. ${ }^{11,37,38}$ Alternatively, patients who respond to treatment and attain biochemical control at the starting dose of octreotide LAR may have their dose decreased.

The following clinical reports present the safety and tolerability results specifically from studies of dose-optimized treatment with somatostatin analogs in patients with acromegaly (Table 1). ${ }^{39-44}$ A study was performed in which 125 patients with acromegaly who had previously received lanreotide slow release (SR) therapy (30 mg/10-14 days) and had either undergone previous pituitary surgery or received pituitary radiation prior to screening were switched to octreotide LAR and, if necessary based on response, were given a dose adjustment 3 months after switching medications. ${ }^{39}$ The results demonstrate that dose titration of octreotide LAR from 20 to $30 \mathrm{mg} / \mathrm{month}$ led to a statistically significant decrease in average GH levels among the participants; however, among patients treated with octreotide LAR (30 $\mathrm{mg} / \mathrm{month}$ ), the number of patients with normalized IGF-1 levels remained the same. The adverse events recorded throughout the study demonstrated that neither the switch in somatostatin analog treatment nor the dose optimization of octreotide LAR caused a significant change in the safety and tolerability results. ${ }^{39}$ A lengthy study of octreotide LAR treatment (up to 54 months) in 110 patients in which 59 patients had received previous treatment (pituitary surgery, radiation, or both) and the remaining had first-line somatostatin analog therapy determined that dose optimization led to a progressive increase in the percentage of patients who achieved IGF-1 normalization. ${ }^{40}$ Additionally, there were no significant changes in routine biochemistry and no clinically meaningful increase in fasting glucose levels. Transient gastrointestinal side effects (nausea and abdominal bloating) were reported in $8 \%$ of the patients and $18 \%$ reported new biliary abnormalities (gallstones or sludge); however, these results were not attributed to a particular octreotide LAR dose and are similar to the expected occurrence following the initial starting dose. A study evaluating octreotide LAR doses of up to $40 \mathrm{mg} / \mathrm{month}$ for a duration of 40 months in patients with persistent acromegaly despite prior surgery or radiotherapy reported that dose-optimized treatment with octreotide LAR improved the number of patients who achieved biochemical 
Table 1. Efficacy and tolerability of dose optimization in patients with acromegaly (continued on next page).

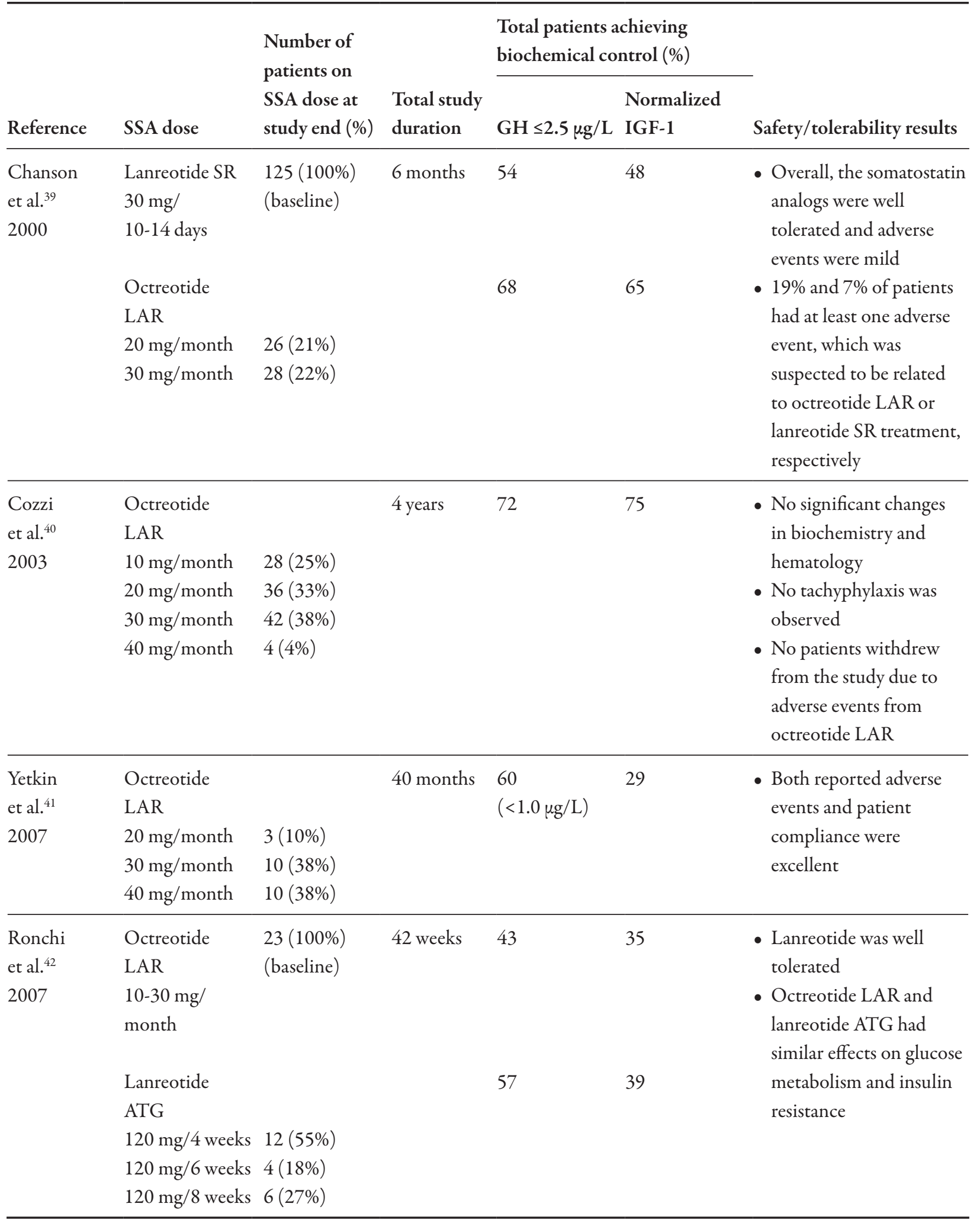


Table 1 (continued). Efficacy and tolerability of dose optimization in patients with acromegaly.

\begin{tabular}{|c|c|c|c|c|c|c|}
\hline \multirow[b]{2}{*}{ Reference } & \multirow[b]{2}{*}{ SSA dose } & \multirow{2}{*}{$\begin{array}{l}\text { Number of } \\
\text { patients on } \\
\text { SSA dose at } \\
\text { study end (\%) }\end{array}$} & \multirow[b]{2}{*}{$\begin{array}{l}\text { Total study } \\
\text { duration }\end{array}$} & \multicolumn{2}{|c|}{$\begin{array}{l}\text { Total patients achieving } \\
\text { biochemical control (\%) }\end{array}$} & \multirow[b]{2}{*}{ Safety/tolerability results } \\
\hline & & & & $\mathrm{GH} \leq 2.5 \mu \mathrm{g} / \mathrm{L}$ & $\begin{array}{l}\text { Normalized } \\
\text { IGF-1 }\end{array}$ & \\
\hline $\begin{array}{l}\text { Chanson } \\
\text { et al. }{ }^{43} \\
2008\end{array}$ & $\begin{array}{l}\text { Lanreotide } \\
\text { depot } \\
60 \mathrm{mg} / \mathrm{month} \\
90 \mathrm{mg} / \mathrm{month} \\
120 \mathrm{mg} / \mathrm{month}\end{array}$ & $\begin{array}{l}9(14 \%) \\
4(6 \%) \\
46(73 \%)\end{array}$ & 48 weeks & 85 & 43 & $\begin{array}{l}\text { - The majority of adverse } \\
\text { events were mild to } \\
\text { moderate in nature } \\
\text { - Treatment did not } \\
\text { significantly increase } \\
\text { glycoregulation }\end{array}$ \\
\hline $\begin{array}{l}\text { Giustina } \\
\text { et al. }{ }^{44} \\
2009\end{array}$ & $\begin{array}{l}\text { Octreotide } \\
\text { LAR } \\
30 \mathrm{mg} / 21 \text { days } \\
60 \mathrm{mg} / 28 \text { days }\end{array}$ & $\begin{array}{l}11(42 \%) \\
15(58 \%)\end{array}$ & 24 weeks & $\begin{array}{l}0 \\
20\end{array}$ & $\begin{array}{l}0 \\
36\end{array}$ & $\begin{array}{l}\text { - } 18 \% \text { of patients reported } \\
\text { transient gastrointestinal } \\
\text { adverse events, all of } \\
\text { which were mild or } \\
\text { moderate } \\
\text { - Patients did not report } \\
\text { a dose-related change in } \\
\text { adverse events }\end{array}$ \\
\hline
\end{tabular}

ATG=Autogel; $\mathrm{GH}=$ growth hormone; $I G F-1=$ insulin-like growth factor-1; $\mathrm{LAR}=$ long-acting repeatable; $S \mathrm{R}=$ slow release; SSA $=$ somatostatin analog.

control. ${ }^{41}$ Despite the high dose of octreotide LAR, the incidence of side effects in all patients was low and patient compliance was high. Gallstones were detected in 12 patients and six patients underwent laparoscopic cholecystectomy. The efficacy of lanreotide depot in decreasing GH and IGF-1 levels was similar to patients treated with octreotide LAR, with the most frequent adverse events being generally mild or moderate and commonly affecting the gastrointestinal system. In addition, glucose levels were not statistically different between studies of octreotide LAR or lanreotide depot, nor did insulin resistance change between treatment with the two somatostatin analogs. ${ }^{42}$ A 48 -week dose-titration study of lanreotide depot was completed by 59 of 63 patients with acromegaly who had received previous somatostatin analog therapy (excluding lanreotide depot), surgery, or radiotherapy determined that dose optimization resulted in normalization of IGF-1 in $43 \%$ of patients and GH levels $\leq 1 \mu \mathrm{g} / \mathrm{L}$ were achieved in $45 \%$ of the patients enrolled in the study. ${ }^{43}$ The majority of adverse events in this study were mild or moderate in severity, with $57 \%$ of patients reporting at least one episode of diarrhea and $27 \%$ of patients reporting abdominal pain. ${ }^{43} \mathrm{~A}$ multicenter study of 26 patients who did not achieve biochemical control (mean baseline GH $\geq 2 \mu \mathrm{g} / \mathrm{L}$ and IGF-1 levels above normal) at the conventional dose (20 mg/month) of octreotide LAR were treated with either high-dose (60 mg/month) or highfrequency (30 mg every 3 weeks) octreotide LAR to achieve control of GH $(<2 \mu \mathrm{g} / \mathrm{L})$ and normalization of IGF-1. ${ }^{44}$ Overall, high-dose treatment with octreotide LAR controlled 
IGF-1 and GH levels in $36 \%$ and $20 \%$, respectively, of patients who were not able to achieve satisfactory biochemical control with conventional somatostatin analog therapy. Fourteen patients experienced an adverse event that was mild to moderate in nature and mainly gastrointestinal; however, these were not determined to be a dose-response effect.

\section{NET}

NET are a diverse group of solid tumors that develop as neoplasms from secretory, neuroendocrine cells throughout the body and comprise about $2 \%$ of all malignant tumors. ${ }^{45}$ Historically, NET were regarded as rare tumors; however, this thinking may have been the result of poor awareness and a lack of specific diagnostic techniques. A recent review of the US Surveillance Epidemiology and End Results (SEER) database by Yao et al. ${ }^{46}$ suggests that the incidence of NET has been steadily increasing, rising from 1.09 new cases/100,000 people in the 1970 s to 5.25 new cases/100,000 people (age-adjusted US 2000 standard population) in 2004. The increase is likely caused by improvements in recognition and classification of this tumor class. ${ }^{46}$ From a diagnostic point of view, identification of NET is a challenge to most physicians because their clinical presentation is subtle and detection may occur secondary to routine colonoscopy, endoscopic procedure, or as part of an autopsy. ${ }^{47}$ Previously, NET were divided into three subtypes (foregut, midgut, and hindgut) based on their embryologic origin (Table 2A); ${ }^{48,49}$ however, recently the practice has changed to classify the tumors based on the location of primary origin, differentiation/tumor-node-metastasis (TNM) grade, and stage (Table 2B). ${ }^{50,51}$ In addition, NET are usually characterized as clinically symptomatic (functioning) or silent (nonfunctioning) tumors, depending on whether the peptides that are secreted produce symptoms. Functioning NET are further classified by the peptides that are secreted into the system

Table 2A. Traditional classification of neuroendocrine tumor by embryological origin.

\begin{tabular}{ll}
\hline Classification & Location \\
\hline Foregut & Thymus, esophagus, lung, stomach, pancreas \\
Midgut & Appendix, ileum, jejunum, cecum, ascending colon \\
Hindgut & Distal large bowel, rectum \\
\hline
\end{tabular}

Table 2B. Current classification of neuroendocrine tumors based on World Health Organisation (WHO) and tumor-nodemetastases (TNM) guidelines.

\begin{tabular}{ll}
\hline Classification & Description \\
\hline Tumor site & Primary tumor location (lung, colon, rectal, etc) \\
Functionality & Characteristic clinical symptoms \\
WHO & Biology of the tumor, differentiation, and size \\
TNM & Stage (location, size, nodes, and metastasis) \\
& Grade (mitotic count and Ki-67 indexing) \\
\hline
\end{tabular}


(eg, serotonin and tachykinins), which can lead to subsequent clinical symptoms in the patient; the most common being carcinoid syndrome. These secondary clinical symptoms may increase morbidity and their adverse events typically can further complicate effective treatment of the patient. Although earlier literature considered about a third of NET to be non-functioning, recent estimates suggest that up to $60 \%$ of NET are non-functioning. ${ }^{52}$ Nonfunctioning NET are more difficult to detect and may only be found after non-specific local effects, such as abdominal symptoms, bowel obstruction, and jaundice due to bile-duct obstruction, arise as a result of tumor growth and metastasis. ${ }^{52,53}$

\section{Management of NET}

Treatment of NET is based on the current stage of the disease, with the primary aim being to prevent tumor progression and reduce the symptoms caused by the secretion of bioactive agents. Treatment is individualized based on the size and location of the tumor and the co-morbidities experienced by the patient. The first-line therapy of choice is surgery and the effectiveness of removing the primary tumor is high if the tumor has not metastasized. Otherwise, surgical debulking of the tumor is common to reduce the symptoms caused by the secondary clinical syndromes; however, removal of the majority of the tumor volume, including the primary tumor if known, is necessary to achieve relief of symptoms. ${ }^{1,49}$ For unresectable tumors, the National Comprehensive Cancer Network (NCCN) recommends the following treatment options: local ablative therapy (ie, radiofrequency ablation), regional therapy (ie, arterial or chemoembolization), cytoreductive surgery, or systemic therapy with cytotoxic agents. Most patients with NET are not responsive to traditional chemotherapy regimens, and cytotoxic agents have not demonstrated an overall survival benefit. ${ }^{10}$ Therefore, medical therapy with somatostatin analogs is a viable option either before or following surgery to provide symptom alleviation, slow tumor progression, and improve the patient's quality of life. ${ }^{54}$ Similar to acromegaly treatment guidelines, the NCCN guidelines have confirmed the benefit of dose optimization and recommend that the patient's clinical response be evaluated relative to the treatment goals and the need for either increased doses of the somatostatin analog for breakthrough symptoms or ongoing dose adjustments to achieve treatment success. ${ }^{49,55}$

\section{Controlling Symptoms of NET with Somatostatin Analogs}

Carcinoid syndrome is the most common syndrome associated with NET and is characterized by symptoms such as flushing, diarrhea, abdominal pain, and right-sided heart failure (Figure 3 ). Greater than $80 \%$ of NET express $\mathrm{sst}_{2}{ }^{56}$ and it is believed the high binding affinities and subsequent activation of this sst by the somatostatin analogs octreotide LAR and lanreotide depot result in the inhibition of hormone secretion as well as the possibility of an antiproliferative effect on the tumor itself. ${ }^{6,57}$ Pooled data from more than 14 trials spanning the past two decades revealed that $>70 \%$ of patients with NET treated with octreotide LAR experienced symptomatic resolution or improvement of diarrhea (40\%-88\%) and flushing (48\%-100\%). ${ }^{1}$ However, objective tumor responses were shown in only three of these trials, with the individual response rates ranging between $3 \%$ and $9 \%$. The therapeutic effects of lanreotide have been studied in 
Figure 3. Carcinoid syndrome and clinical complications of neuroendocrine tumors.

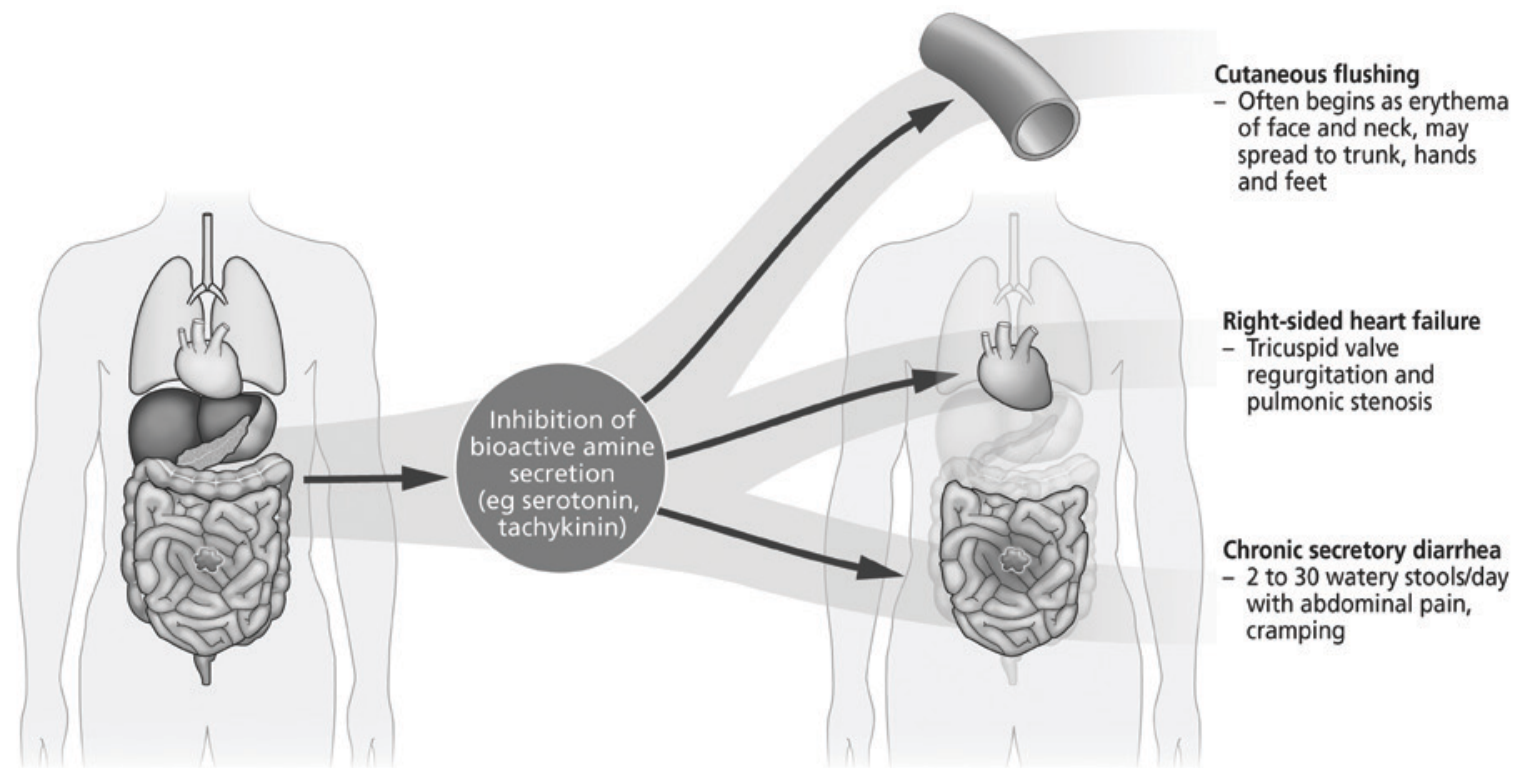

11 trials totaling about 300 patients over the past decade. The symptomatic improvement in diarrhea and flushing (36\%-100\% and 38\%$100 \%$, respectively) was similar to that with octreotide, as was the objective tumor response (0\%-9\%). ${ }^{1}$ Recently, the antiproliferative effect of medical therapy was confirmed in a study comparing the control of tumor growth by octreotide LAR (30 mg/28 days) versus placebo in patients with metastatic NET of the midgut (Placebo-controlled prospective Randomized study on the antiproliferative efficacy of Octreotide LAR in patients with metastatic neuroendocrine MIDgut tumors [PROMID] study). Treatment with octreotide LAR led to a significant increase in time to tumor progression ( 14.3 vs. 6.0 months; $P=0.0008$ ). ${ }^{58}$ As a whole, these studies have demonstrated the efficacy of somatostatin analog therapy for controlling the symptoms associated with NET and slowing tumor progression, but draw attention to the need for dose optimization to improve symptom control in a greater percentage of patients.

\section{Safety and Tolerability of Dose Optimization in Patients with NET}

Conventional somatostatin analog doses are extremely well tolerated by patients with NET and are rarely the cause for discontinuation of therapy. The safety of octreotide LAR (20 mg) in the treatment of NET was initially evaluated in one phase 3 study of 93 patients with carcinoid syndrome. ${ }^{59}$ The adverse events experienced by $>15 \%$ of patients treated with octreotide LAR included headache, nausea, and dizziness. Additionally, patients experienced generalized pain, arthropathy, rash, and fatigue. Routine biochemical and hematological markers should be monitored in patients treated with somatostatin analogs and do not change significantly due to treatment; however, patients with diabetes mellitus should be monitored carefully for co-morbid conditions. Treatment with depot formulations of somatostatin analogs, such as octreotide LAR and lanreotide depot, pose a risk of cholelithiasis and biliary tract changes, including gallstones, sediment, 
and sludge. The efficacy of somatostatin analogs, such as octreotide and lanreotide, was described in a dose-titration study, which determined that octreotide subcutaneous doses $>500 \mu \mathrm{g}$ (500-2000 $\mu \mathrm{g}$ ) three times daily resulted in improved carcinoid syndrome control and exhibited a greater response rate, defined as a $50 \%$ reduction in tumor diameter, in 31\% of patients compared to historical controls (20\%). This early study of "high-dose therapy" also established the safety and tolerability of dose optimization in patients with NET who experience unresponsive or breakthrough symptoms. ${ }^{59}$

A review of the recent literature shows that patients treated with a range of somatostatin analog doses do not experience any difference in common adverse events when compared to initial dosing (Table 3). ${ }^{60-62}$ A 6-month trial of 71 patients with carcinoid syndrome that was not controlled by previous somatostatin analog therapy or surgery measured the efficacy and safety of lanreotide depot dose titration based on symptom response. ${ }^{60}$ The study determined that dose optimization caused flushing and diarrhea episodes to decrease significantly from baseline by a mean of 1.3 and 1.1 episodes/day, respectively (both $P=0.001)$. In total, $37 \%$ of patients reported adverse events attributed to treatment with lanreotide depot. The most frequent side effects were abdominal pain (38\%), diarrhea (17\%), fatigue (15\%), vomiting (13\%), asthenia $(11 \%)$, nausea $(10 \%)$, cholelithiasis

Table 3. Efficacy and tolerability of dose optimization in patients with neuroendocrine tumors.

\begin{tabular}{|c|c|c|c|c|c|}
\hline Reference & SSA dose & $\begin{array}{l}\text { Number of } \\
\text { patients on SSA } \\
\text { dose at study } \\
\text { end (\%) }\end{array}$ & $\begin{array}{l}\text { Total study } \\
\text { duration }\end{array}$ & $\begin{array}{l}\text { Efficacy: prevention of } \\
\text { target symptoms }\end{array}$ & Safety/tolerability results \\
\hline $\begin{array}{l}\text { Ruszniewski } \\
\text { et al. } .^{60} \\
2004\end{array}$ & $\begin{array}{l}\text { Lanreotide SR } \\
60 \mathrm{mg} / \text { month } \\
90 \mathrm{mg} / \text { month } \\
120 \mathrm{mg} / \text { month }\end{array}$ & $\begin{array}{l}15(21 \%) \\
11(16 \%) \\
45(63 \%)\end{array}$ & 6 months & $\begin{array}{l}\text { - } 65 \% \text { ( } \geq 50 \% \text { reduction } \\
\text { in flushing) } \\
\text { - } 18 \%(\geq 50 \% \text { reduction } \\
\text { in diarrhea) }\end{array}$ & $\begin{array}{l}\text { - The most frequent } \\
\text { side effects were } \\
\text { gastrointestinal } \\
\text { - Severe adverse events } \\
\text { were reported by } 10 \% \\
\text { of the patients }\end{array}$ \\
\hline $\begin{array}{l}\text { Rosenoff } \\
\text { et al. }^{61} \\
2006\end{array}$ & $\begin{array}{l}\text { Octreotide LAR } \\
30 \mathrm{mg} / \mathrm{month} \\
40 \mathrm{mg} / \mathrm{month}\end{array}$ & $\begin{array}{l}72(48 \%) \\
77(52 \%)\end{array}$ & 6 months & $\begin{array}{l}\text { - } 62 \% \text { reported severe } \\
\text { diarrhea } \\
\text { - } 48 \% \text { reported severe } \\
\text { diarrhea }\end{array}$ & $\begin{array}{l}\text { - Adverse events were } \\
\text { balanced between doses } \\
\text { - No differences in } \\
\text { quality of life or } \\
\text { treatment satisfaction } \\
\text { were measured between } \\
\text { groups }\end{array}$ \\
\hline 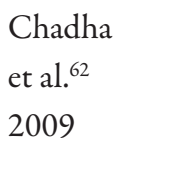 & $\begin{array}{l}\text { Octreotide LAR } \\
20-30 \mathrm{mg} / \text { month } \\
60-90 \mathrm{mg} / \text { month }\end{array}$ & $\begin{array}{l}24(44 \%) \\
30(56 \%)\end{array}$ & & $\begin{array}{l}\text { - } 0.77 \text { ( } 1 \text { year survival }) \\
\text { - } 0.88 \text { ( } 1 \text { year survival })\end{array}$ & $\begin{array}{l}\text { Dose escalation of } \\
\text { octreotide LAR up to } \\
\text { high doses }(90 \mathrm{mg}) \text { was } \\
\text { well tolerated }\end{array}$ \\
\hline
\end{tabular}

LAR=long-acting repeatable; $S R=$ slow release; $S S A=$ somatostatin analog. 
(10\%), and anorexia (10\%). ${ }^{60} \mathrm{~A}$ trial designed to compare two dose levels of octreotide LAR (30 and $40 \mathrm{mg} / \mathrm{month}$ ) highlighted the ability of octreotide LAR to control diarrhea in patients with active or prior chemotherapy-induced diarrhea. ${ }^{61}$ Fewer patients in the $40 \mathrm{mg} / \mathrm{month}$ group compared with those in the $30 \mathrm{mg}$ / month group experienced severe diarrhea ( $62 \%$ vs. $48 \% ; P=0.14$ ), required intravenous fluid ( $32 \%$ vs. $19 \%$; $P=0.10$ ), or had diarrhearelated unscheduled healthcare visits (42\% vs. $28 \% ; P=0.11$ ). No significant differences were observed between the treatment groups in either measured quality of life or treatment satisfaction. Most importantly, adverse events were balanced between the two groups. ${ }^{61}$ Finally, a retrospective analysis studied the efficacy and tolerability of higher doses (>30 mg/month) of octreotide LAR in 54 patients with pancreatic NET. ${ }^{62}$ Patients were subdivided into two groups for analysis: those who received only the conventional dose of octreotide LAR $(n=24)$, and those who started with the conventional dose but required dose escalation ( $n=34)$. No treatment-related toxicities were seen in either group, with octreotide LAR being well tolerated at higher doses. Relief from diarrhea and flushing, reduction in tumor volume, and improvements in quality of life in patients with NET can be achieved by dose optimization of somatostatin analog therapy without a significant change in safety and tolerability. ${ }^{62}$

\section{DISCUSSION}

Dose optimization with somatostatin analogs has been shown to be an effective means to improve treatment outcomes in patients with either acromegaly or NET who have inadequate response to the starting dose or fail to achieve complete control of their disease. Octreotide LAR, the most widely used somatostatin analog, is generally effective with reported side effects being mild to moderate. When compared to the initial somatostatin analog dose, dose increase did not cause noteworthy differences in adverse events or tolerability; however, titration did provide a beneficial improvement in efficacy. Additionally, in studies of high-dose treatment with octreotide LAR ( $>40 \mathrm{mg} / \mathrm{month}$ ) or lanreotide ( $>120 \mathrm{mg} / \mathrm{month})$, there was not a considerable rise in reported adverse events. From a clinical perspective, dose optimization is most commonly used to treat breakthrough symptoms that become more persistent and frequent in the time period immediately prior to the next monthly dose. As clinicians, we utilize the consensus guidelines discussed in this document as the suitable framework to follow when titrating the patient's dose. The safety and tolerability of high-dose treatment with somatostatin analogs has been established in these treatment guidelines and the studies reviewed show an added efficacy benefit without increased safety concerns.

\section{ACKNOWLEDGMENTS}

W.H.L. has received research support from Novartis Pharmaceuticals Corporation and Indevus Pharmaceuticals and has served as a consultant for Pfizer, Indevus, Ipsen, and Novartis. L.A. has received research support from Pfizer, Novartis, and ImClone and has served as consultant for Pfizer, Novartis, Molecular Insight Pharmaceuticals, and Roche. The authors did not receive any financial support for the conceptualization, writing, or submission of this manuscript. The authors thank Timothy Remus, PhD, for providing editorial assistance in the preparation of this manuscript. Financial support for editorial assistance was provided directly to Mudskipper Inc. by Novartis Pharmaceutical Corporation. 
Open Access. This article is distributed under the terms of the Creative Commons Attribution Noncommercial License which permits any noncommercial use, distribution, and reproduction in any medium, provided the original authors and source are credited.

\section{REFERENCES}

1. Modlin IM, Latich I, Kidd M, Zikusoka M, Eick G. Therapeutic options for gastrointestinal carcinoids. Clin Gastroenterol Hepatol. 2006;4:526-547.

2. Webb SM. Quality of life in acromegaly. Neuroendocrinology. 2006;83:224-229.

3. Melmed S, Colao A, Barkan A, et al. Guidelines for acromegaly management: an update. J Clin Endocrinol Metab. 2009;94:1509-1517.

4. Janson ET, Sorbye H, Welin S, et al. Nordic Guidelines 2010 for diagnosis and treatment of gastroenteropancreatic neuroendocrine tumours. Acta Oncol. 2010;49:740-756.

5. Anthony L, Freda PU. From somatostatin to octreotide LAR: evolution of a somatostatin analogue. Curr Med Res Opin. 2009;25:2989-2999.

6. Bauer W, Briner U, Doepfner W, et al. SMS 201-995: a very potent and selective octapeptide analogue of somatostatin with prolonged action. Life Sci. 1982;31:1133-1140.

7. Delaunoit T, Rubin J, Neczyporenko F, Erlichman C, Hobday TJ. Somatostatin analogues in the treatment of gastroenteropancreatic neuroendocrine tumors. Mayo Clin Proc. 2005;80:502-506.

8. Schmid HA. Pasireotide (SOM230): development, mechanism of action and potential applications. Mol Cell Endocrinol. 2008;286:69-74.

9. Melmed S, Casanueva F, Cavagnini F, et al. Consensus statement: medical management of acromegaly. Eur J Endocrinol. 2005;153:737-740.

10. NCCN Practice Guidelines in Oncology ${ }^{\mathrm{TM}}$ Neuroendocrine Tumors (Version 1.0). (C) 2011 National Comprehensive Cancer Network, Inc. 2011. Available at: http://www.nccn.org. Last accessed September 5, 2011.

11. Oberg K. Neuroendocrine tumors. Ann Oncol. 2004;15:iv293-iv2989.
12. Daly AF, Rixhon M, Adam C, Dempegioti A, Tichomirowa MA, Beckers A. High prevalence of pituitary adenomas: a cross-sectional study in the province of Liege, Belgium. J Clin Endocrinol Metab. 2006;91:4769-4775.

13. Holdaway IM, Rajasoorya C. Epidemiology of acromegaly. Pituitary. 1999;2:29-41.

14. Schneider HJ, Sievers C, Saller B, Wittchen HU, Stalla GK. High prevalence of biochemical acromegaly in primary care patients with elevated IGF-1 levels. Clin Endocrinol (Oxf). 2008;69:432-435.

15. Melmed S. Medical progress: Acromegaly. N Engl J Med. 2006;355:2558-2573.

16. Ayuk J, Sheppard MC. Does acromegaly enhance mortality? Rev Endocr Metab Disord. 2008;9:33-39.

17. Holdaway IM, Bolland MJ, Gamble GD. A metaanalysis of the effect of lowering serum levels of GH and IGF-I on mortality in acromegaly. Eur J Endocrinol. 2008;159:89-95.

18. Biermasz NR, Pereira AM, Smit JW, Romijn JA, Roelfsema F. Morbidity after long-term remission for acromegaly: persisting joint-related complaints cause reduced quality of life. J Clin Endocrinol Metab. 2005;90:2731-2739.

19. Holdaway IM, Rajasoorya RC, Gamble GD. Factors influencing mortality in acromegaly. J Clin Endocrinol Metab. 2004;89:667-674.

20. Colao A, Ferone D, Marzullo P, Lombardi G. Systemic complications of acromegaly: epidemiology, pathogenesis, and management. Endocr Rev. 2004;25:102-152.

21. AACE Acromegaly Guidelines Task Force. AACE Medical Guidelines for Clinical Practice for the diagnosis and treatment of acromegaly. Endocr Pract. 2004;10:213-225.

22. Giustina A, Barkan A, Casanueva FF, et al. Criteria for cure of acromegaly: a consensus statement. J Clin Endocrinol Metab. 2000;85:526-529.

23. Beauregard C, Truong U, Hardy J, Serri O. Longterm outcome and mortality after transsphenoidal adenomectomy for acromegaly. Clin Endocrinol (Oxf). 2003;58:86-91.

24. De P, Rees DA, Davies N, et al. Transsphenoidal surgery for acromegaly in wales: results based on stringent criteria of remission. J Clin Endocrinol Metab. 2003;88:3567-3572. 
25. Nomikos P, Buchfelder M, Fahlbusch R. The outcome of surgery in 668 patients with acromegaly using current criteria of biochemical "cure". Eur J Endocrinol. 2005;152:379-387.

26. Shimon I, Cohen ZR, Ram Z, Hadani M. Transsphenoidal surgery for acromegaly: endocrinological follow-up of 98 patients. Neurosurgery. 2001;48:1239-1243.

27. Carlsen SM, Lund-Johansen M, Schreiner T, et al. Preoperative octreotide treatment in newly diagnosed acromegalic patients with macroadenomas increases cure short-term postoperative rates: a prospective, randomized trial. J Clin Endocrinol Metab. 2008;93:2984-2990.

28. Colao A, Pivonello R, Auriemma RS, et al. Predictors of tumor shrinkage after primary therapy with somatostatin analogues in acromegaly: a prospective study in 99 patients. J Clin Endocrinol Metab. 2006;91:2112-2118.

29. Melmed S, Sternberg R, Cook D, et al. A critical analysis of pituitary tumor shrinkage during primary medical therapy in acromegaly. J Clin Endocrinol Metab. 2005;90:4405-4410.

30. Freda PU, Katznelson L, van der Lely AJ, Reyes CM, Zhao S, Rabinowitz D. Long-acting somatostatin analog therapy of acromegaly: a meta-analysis. J Clin Endocrinol Metab. 2005;90:4465-4473.

31. Novartis Sandostatin $\operatorname{LAR}^{\circledR}$ Depot (octreotide acetate for injectable suspension) prescribing information. 2010. Available at: http://www.pharma.us. novartis.com/product/pi/pdf/sandostatin_lar.pdf. Last accessed September 5, 2011.

32. Ayuk J, Sheppard MC. Growth hormone and its disorders. Postgrad Med J. 2006;82:24-30.

33. Somatuline Depot (lanreotide) injection prescribing information. Somatuline Depot (lanreotide) injection prescribing information. Ipsen. 2007.

34. Caron P, Morange-Ramos I, Cogne M, Jaquet P. Three year follow-up of acromegalic patients treated with intramuscular slow-release lanreotide. J Clin Endocrinol Metab. 1997;82:18-22.

35. Chen T, Miller TF, Prasad P, et al. Pharmacokinetics, pharmacodynamics, and safety of microencapsulated octreotide acetate in healthy subjects. J Clin Pharmacol. 2000;40:475-481.

36. Giusti M, Ciccarelli E, Dallabonzana D, et al. Clinical results of long-term slow-release lanreotide treatment of acromegaly. Eur J Clin Invest. 1997;27:277-284.
37. Colao A, Lombardi G. Dose optimization of somatostatin analogues for acromegaly patients. J Endocrinol Invest. 2010;33:125-127.

38. Turner HE, Thornton-Jones VA, Wass JA. Systematic dose-extension of octreotide LAR: the importance of individual tailoring of treatment in patients with acromegaly. Clin Endocrinol (Oxf). 2004;61:224-231.

39. Chanson P, Boerlin V, Ajzenberg C, et al. Comparison of octreotide acetate LAR and lanreotide SR in patients with acromegaly. Clin Endocrinol (Oxf). 2000;53:577-586.

40. Cozzi R, Attanasio R, Montini M, et al. Four-year treatment with octreotide-long-acting repeatable in 110 acromegalic patients: predictive value of short-term results? J Clin Endocrinol Metab. 2003;88:3090-3098.

41. Yetkin DO, Boysan SN, Tiryakioglu O, Yalin AS, Kadioglu P. Forty-month follow-up of persistent and difficultly controlled acromegalic patients treated with depot long acting somatostatin analog octreotide. Endocr J. 2007;54:459-464.

42. Ronchi CL, Boschetti M, Uberti EC, et al. Efficacy of a slow-release formulation of lanreotide (Autogel $120 \mathrm{mg}$ ) in patients with acromegaly previously treated with octreotide long acting release (LAR): an open, multicentre longitudinal study. Clin Endocrinol (Oxf). 2007;67:512-519.

43. Chanson P, Borson-Chazot F, Kuhn J-M, Blumberg J, Maisonobe P, Delemer B. Control of IGF-I levels with titrated dosing of lanreotide Autogel over 48 weeks in patients with acromegaly. Clin Endocrinol (Oxf). 2008;69:299-305.

44. Giustina A, Bonadonna S, Bugari G, et al. Highdose intramuscular octreotide in patients with acromegaly inadequately controlled on conventional somatostatin analogue therapy: a randomised controlled trial. Eur J Endocrinol. 2009;161:331-338.

45. Öberg K, Kvols L, Caplin M, et al. Consensus report on the use of somatostatin analogs for the management of neuroendocrine tumors of the gastroenteropancreatic system. Ann Oncol. 2004;15:966-973.

46. Yao JC, Hassan M, Phan A, et al. One hundred years after "carcinoid": epidemiology of and prognostic factors for neuroendocrine tumors in 35,825 cases in the United States. J Clin Oncol. 2008;26:3063-3072.

47. Berge T, Linell F. Carcinoid tumours. Frequency in a defined population during a 12-year period. Acta Pathol Microbiol Scand A. 1976;84:322-330. 
48. Klöppel G, Perren A, Heitz PU. The gastroenteropancreatic neuroendocrine cell system and its tumors: the WHO classification. Ann N Y Acad Sci. 2004;1014:13-27.

49. Plockinger U, Rindi G, Arnold R, et al. Guidelines for the diagnosis and treatment of neuroendocrine gastrointestinal tumours. A consensus statement on behalf of the European Neuroendocrine Tumour Society (ENETS). Neuroendocrinology. 2004;80:394-424.

50. Rindi G, Kloppel G, Alhman H, et al. TNM staging of foregut (neuro)endocrine tumors: a consensus proposal including a grading system. Virchows Arch. 2006;449:395-401.

51. Rindi G, Kloppel G, Couvelard A, et al. TNM staging of midgut and hindgut (neuro) endocrine tumors: a consensus proposal including a grading system. Virchows Arch. 2007;451:757-762.

52. Modlin IM, Moss SF, Chung DC, Jensen RT, Snyderwine E. Priorities for improving the management of gastroenteropancreatic neuroendocrine tumors. J Natl Cancer Inst. 2008;100:1282-1289.

53. Kaltsas GA, Besser GM, Grossman AB. The diagnosis and medical management of advanced neuroendocrine tumors. Endocr Rev. 2004;25:458-511.

54. Modlin IM, Oberg $\mathrm{K}$, Chung DC, et al. Gastroenteropancreatic neuroendocrine tumours. Lancet Oncol. 2008;9:61-72.

55. Kvols LK, Brendtro KL. The North American Neuroendocrine Tumor Society (NANETS) guidelines: mission, goals, and process. Pancreas. 2010;39:705-706.
56. Papotti M, Croce S, Bellò $M$, et al. Expression of somatostatin receptor types 2, 3 and 5 in biopsies and surgical specimens of human lung tumours. Correlation with preoperative octreotide scintigraphy. Virchows Arch. 2001;439:787-797.

57. Lamberts SW, van der Lely AJ, de Herder WW, Hofland LJ. Octreotide. N Engl J Med. 1996;334:246-254.

58. Rinke A, Müller H-H, Schade-Brittinger C, et al. Placebo-controlled, double-blind, prospective, randomized study of the effect of octreotide LAR in the control of tumor growth in patients with metastatic neuroendocrine midgut tumors: a report from the PROMID study group. J Clin Oncol. 2009;27:4656-4663.

59. Anthony L, Johnson D, Hande K, et al. Somatostatin analogue phase I trials in neuroendocrine neoplasms. Acta Oncol. 1993;32:217-223.

60. Ruszniewski P, Ish-Shalom S, Wymenga $\mathrm{M}$, et al. Rapid and sustained relief from the symptoms of carcinoid syndrome: results from an open 6-month study of the 28-day prolonged-release formulation of lanreotide. Neuroendocrinology. 2004;80:244-251.

61. Rosenoff SH, Gabrail NY, Conklin R, et al. A multicenter, randomized trial of long-acting octreotide for the optimum prevention of chemotherapy-induced diarrhea: results of the STOP trial. J Support Oncol. 2006;4:289-294.

62. Chadha MK, Lombardo J, Mashtare T, et al. High-dose octreotide acetate for management of gastroenteropancreatic neuroendocrine tumors. Anticancer Res. 2009;29:4127-4130. 